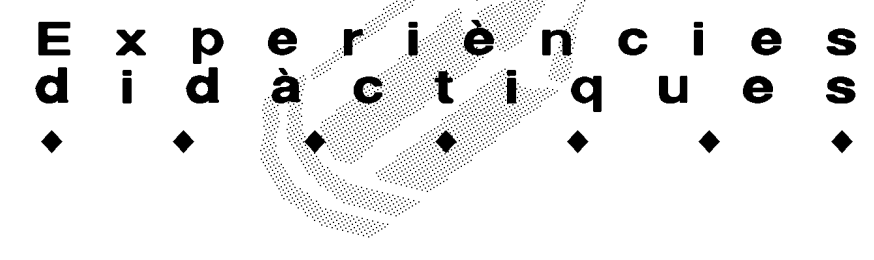

\title{
LA CIÈNCIA DE LA PSEUDOCIÈNCIA ASTROLÒGICA
}

\author{
Agustí Salvat Altés. Àrea de Didàctica de les Ciències Experimentals. URV
}

Segons els adeptes a les pseudociències, l'astrologia "és la ciència que estudia els astres des del punt de vista de la relació que hi ha entre els fenòmens del cel $i$ l'esdevenir quotidià de la humanitat. A diferència del mètode científic, que s'utilitza des de fa ben just un parell de segles, el caràcter de ciència de l'astrologia es fonamenta en les observacions que l'ésser humà ha fet a través de milers d'anys, des dels temps babilònics fins a l'actualitat; observacions profundes realitzades per savis i cultures de diferents tipus que, d'acord amb els resultats comprovats, arribaren a la mateixa conclusió respecte a la correlació existent entre les posicions planetàries i la vida de l'ésser humà i del seu món" (www.redastral.com).

No s'ha de confondre l'astrologia amb l'astronomia, que sí és una ciència i que s'encarrega de l'estudi sistemàtic dels astres. En altres paraules, l'astronomia i especialment l'astrofísica, tracten de descriure i comprendre el comportament i destí dels planetes, estrelles i galàxies que componen l'univers observable.

L'astrologia també s'interessa per alguns cossos celests, però de forma diferent, ja que es fonamenta, simplement, en la creença que determinades configuracions d'un nombre de planetes, dins d'un nombre limitat de sectors arbitraris del cel (signes zodiacals i cases) produeixen una influència definida sobre esdeveniments terrestres com el destí personal, el d'un animal, el d'un objecte, el d'una empresa o el d'un país.

\section{Exploració astrològica entre alumnes universitaris}

Si he de ser sincer, mai no havia pensat fer una prova astrològica amb ningú, i encara menys amb alumnes universitaris. De fet, la idea se'm va ocórrer una tarda, quan em trobava en una llibreria, remenant llibres. Un parell de joves universitàries, d'uns vint anys, també feien el mateix que jo, però a la prestatgeria del costat, a la d'astrologia i derivats esotèrics. De sobte vaig sentir que una li deia a l'altra: -Però tu el que vols és que l'amor et vaigi bé, no? L'altra contestà: -Sí!l la primera li aconsellà en to imperatiu: -Doncs, agafa aquest llibre! Finalment, la dubitativa noia li féu cas i l'agafà, confiant, potser, que l'empresa amorosa arribaria a bon port.
A fi i efecte de veure fins a quin punt els alumnes universitaris creuen que l'astrologia és capaç d'endevinar el futur d'una persona, es va fer una exploració astrològica entre els alumnes de segon curs de Magisteri (de les especialitats d'Educació Musical, Educació Física, Educació Primària i Llengües Estrangeres) de la Facultat de Ciències de l'Educació i Psicologia de Tarragona. En total hi intervingueren 96 alumnes (78 del sexe femení $i$ 18 del masculí). Les edats oscil-laven des dels 19 anys ( 1 alumne) fins als 36 ( 2 alumnes), encara que la majoria d'ells tenien edats compreses entre els 20 i 22 anys (70 alumnes).

L'exploració consistí a donar-los l'horòscop que publicà el «Diari de Tarragona» el dia 7 de maig del 2001 i demanar-los que contestessin un seguit de preguntes. Per sistematitzar la recollida de dades, l'horòscop de cada signe zodiacal estava desglossat en tres parts: la primera feia referència a qüestions de salut; la segona, a aspectes econòmics; i la tercera, al terreny amorós.

A la primera pregunta es demanava que diguessin si l'horòscop havia endevinat què els havia passat el dia anterior (la prova es realitzà el dia 8 de maig). Els resultats foren aquests: En el tema de la salut, 43 "consideraren" que l'horòscop ho havia endevinat, mentre que 53 digueren que no. Pel que fa a les qüestions econòmiques, 23 consideraren que l'havia encertat i 73 que no. En el camp amorós, 25 digueren que "sí" i 71 que "no".

En conjunt, la capacitat predictiva de l'horòscop resultà més aviat pobra, perquè va tenir un èxit d'encert de l'ordre d'1/3.

A la segona qüestió s'explicava, de forma breu, com es fa la carta astral d'una persona i se'ls demanava que diguessin si la carta astral tenia més, menys o les mateixes possibilitats de predir el futur que l'horòscop. 66 d'ells pensen que la carta astral té les mateixes possibilitats endivinatòries que l'horòscop; 27 creuen que en té més la carta astral i 2 diuen que és l'horòscop qui en té més. Hi ha un alumne que no contesta.

La tercera pregunta intentava esbrinar si les estrelles de les diferents constel-lacions del zodíac tenen alguna mena d'influència (en el moment del naixement) sobre el caràcter, forma de ser i destí de les persones. El resultat obtingut és semblant al de la segona pregunta: 


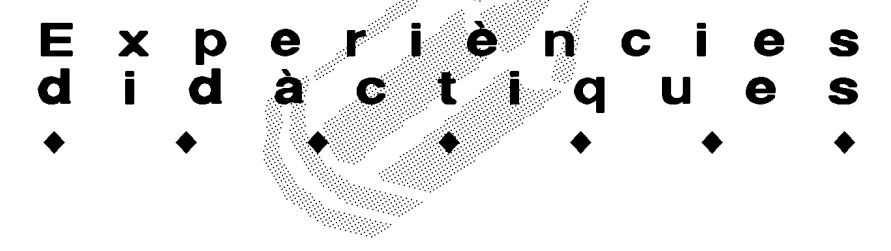

27 creuen que sí i 69 diuen que no.

A l'última qüestió -la quarta-, es preguntava si alguns planetes i satèl-lits del sistema solar tenen alguna mena d'influència (en el moment del naixement) sobre el caràcter, forma de ser i destí de les persones. 69 alumnes digueren que no mentre que 27 consideraren que sí.

\section{Les constel-lacions $\mathrm{i}$ els signes zodiacals}

El zodíac és una banda de l'esfera celest que té una amplada d'uns $17^{\circ}$, la qual és travessada longitudinalment per una línia anomenada eclíptica, que la divideix en dues meitats iguals. El Sol ressegueix l'eclíptica completament en 12 mesos, i per això els antics consideraren el zodíac dividit en 12 rectangles iguals, coneguts amb el nom de signes del zodíac. Cadascun d'aquests rectangles té una longitud de $30^{\circ} \mathrm{i}$ el Sol resta al seu interior durant un mes (Fig. 1).

Per conveni, es considera que el Sol comença la seva volta aparent del cel quan entra al signe d'Àries (equinocci de primavera). L'ordre dels restants signes és donat per l'ordre en què el Sol els va travessant durant el seu moviment aparent (de Taure fins a Àries).

Els estels que hi havia dintre de cada signe foren agrupats, a l'antiguitat, en constel.lacions, a les quals es féu correspondre una figura d'acord amb la seva disposició al firmament. Les constel-lacions i els signes que les contenien foren batejats amb el mateix nom. El nom de zodíac prové del fet que les denominacions dels dotze signes corresponen a dibuixos d'éssers vius, llevat del cas de la Balança.

Des d'un punt de vista astronòmic, el zodíac té importància perquè el moviment aparent del Sol, la Lluna i de la majoria de planetes i asteroides té lloc al seu interior.

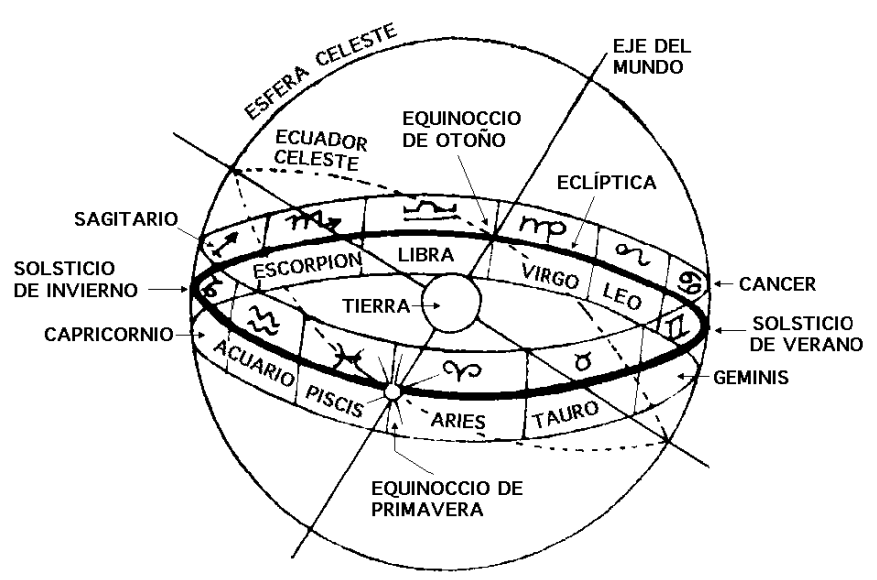

Figura 1. El zodíac i l'eclíptica (HINOSTROZA, 1972)

\section{Incoherències zodiacals}

\section{L 'astrologia tropical i la sidèria}

La correspondència entre signe zodiacal i constel-lació, que tenia lloc en temps d'Hiparc ( 150 a.C.), ja no es dóna actualment, perquè, a causa del moviment de precessió dels equinoccis, cada signe conté la constel.lació anterior: Quan es diu que el Sol ha entrat en el signe d'Àries, l'astre és realment a la constel.lació dels Peixos. Aquesta diferència entre els signes i les constel-lacions anirà augmentant cada cop més, i fins al cap d'uns 25800 anys no hi tornarà a haver coincidència. Amb l'ajut d'un planetari virtual (KINDERSLEY, 1996 ) es pot veure aquesta discordança entre la posició aparent del Sol sobre cada constel-lació i el zodíac. No es pot al.legar que el fenomen és poc conegut, perquè el moviment de precessió dels equinoccis es coneix des de l'època d'Hiparc.

Sembla que la discrepància anterior no representa cap mena de problema per als astròlegs tropicals, ja que, segons Hinostroza (1972): "Las consecuencias de la precesión de los equinoccios sobre la astrología son nulas; la experiencia demuestra que si bien el punto Vernal cae ahora sobre Piscis, los efectos del Sol siguen correspondiendo a su entrada en la constelació de Aries. Es decir, que la Astrología, a partir de ese fenómeno, hace una neta diferencia entre constelación y signo... De modo que se considera que el Sol, en el equinoccio de primavera, entra en el signo de Aries, que viene a ser un segmento virtual del Zodíaco, detrás del cual está ahora Piscis, pero podría estar en cualquier otra constelación sin alterar el sistema astrológico".

La trampa, en aquest cas, consisteix a deslligar els signes de les constel-lacions. Així, els signes passen de la virtualitat a tenir una existència real, configurant una segona franja per sota de la franja zodiacal, amb la capacitat de girar fins al lloc que li interessi al corpus astrològic de torn.

Aquesta escola astrològica, que considera el zodíac de la mateixa forma que quan es va definir a l'època mesopotàmica, s'anomena astrologia tròpica i és la que predomina a la majoria de països, llevat dels anglosaxons, on també existeix una altra escola: l'astrologia sidèria.

L'astrologia sidèria té en compte el moviment de les constel-lacions originat per la precessió del equinnoccis. Així s'evita el problema de la no correspondència entre signes zodiacals i constel-lacions.

El fet d'existir les dues concepcions anteriors -la tròpica i la sidèria- provoca contradiccions serioses entre ambdues. A títol d'exemple pot dir-se que quan es comparen el dos zodíacs, el signe de la Verge de l'astrologia sidèria, a la tròpica abasta una part dels seus 


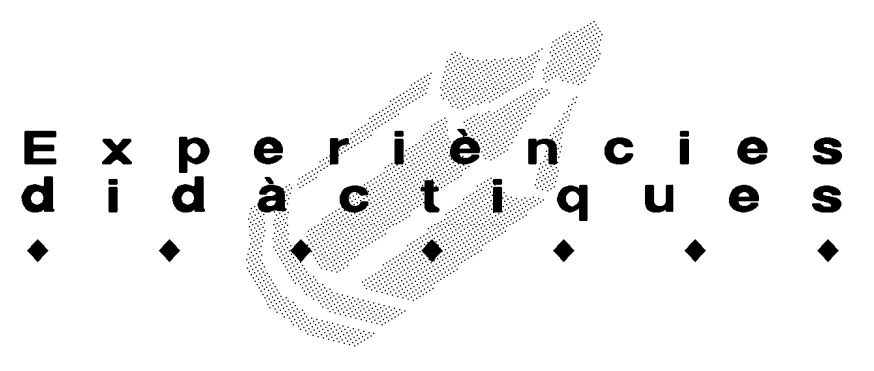

Escorpins, a tots els Balança i només a una petita part dels seus Verge.

\section{Els "objectes familiars" i les constel/lacions}

Deixant de banda la discrepància entre signes $i$ constel-lacions a l'escola tropical, sembla que els astròlegs creuen que les constel-lacions tenen existència real i que aquestes formes imaginades al cel són úniques. Potser creuen que les constel-lacions són objectes plans (és a dir, que totes les seves estrelles són a la mateixa distància de la Terra) $i$ que hi ha alguna mena de lligadura entre elles. Al cel no hi ha cap balança, ni cap verge, ni cap lleó, ni cap de les línies que dibuixen aquestes figures. Totes les formes dibuixades al cel són producte de la imaginació humana, i cada cultura ha creat la seva pròpia interpretació del mateix cel estrellat. ¿Què hauria passat si algú hagués dibuixat una formiga en lloc d'un lleó? ¿Ara, els Lleó tindrien una personalitat tan insignificant com la de les formigues?

El concepte de "personatge o cosa familiar" per definir les diferents constel-lacions és massa relatiu, ja que depèn de "familiar per a qui". A la figura 2 hi ha el dibuix d'un grup d'estrelles visibles a l'hemisferi nord. Aquest conjunt ha estat associat a una cullera pels francesos, a la cua d'un ós pels pobles del nord d'Europa i a un carro celestial pels xinesos. El lector, amb suficient imaginació, hi podrà veure des d'un dinosaure... a una mosca!

Quan al segle XVII es començà a estudiar el cel de l'hemisferi sud, els astrònoms europeus encarregats de fer-ho hi van "veure" objectes "familiars" com: el micro-

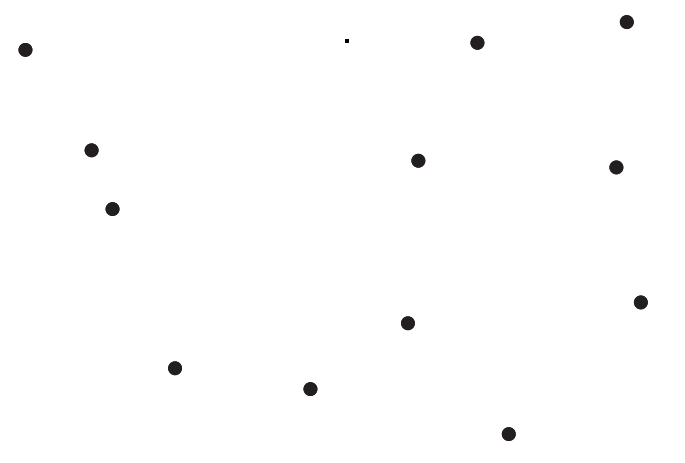

Figura 2. Grup d'estrelles, visibles a l'hemisferi nord

scopi, la brúixola, l'astrolabi i resta d'invents de l'època. Mentrestant, els aborígens australians ja tenien batejades les constel-lacions amb noms com el cangur i l'estruç.

\section{Astrologia local}

Les estrelles estan ubicades en un espai tridimensional, per això quan es projecta en un pla bidimensional (que és la base de la seva aparença al cel) es perd una dimensió, amb el conseqüent canvi d'aparença. Això vol dir que la projecció bidimensional d'una construcció tridimensional varia segons el punt de vista de l'observador. A la figura 3 es mostra un grup fictici de tres estrelles que pot servir com a exemple. La figura 3 (a) mostra el grup d'estrelles "vistes de cara", mentre que la 3 (b) ensenya el mateix grup d'estrelles "vistes de costat".

En el cas que les constel-lacions tinguessin existència real, només serien vàlides des de la Terra, ja que des d'un altre planeta les coses es veurien de forma ben distinta. Això converteix l'astrologia en un "ciència" completament local quan es miren les coses a escala còsmica.

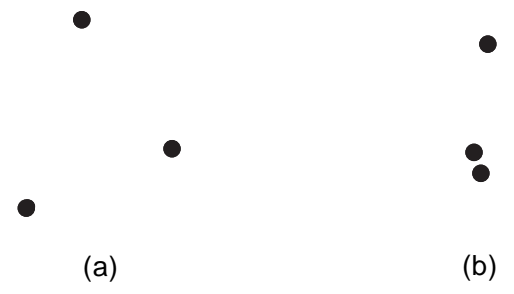

Fig. 3. Diferents aspectes d'un mateix grup d'estrelles, en funció de la posició de l'observador. "De cara" (a) i "de costat" (b)

\section{Les constel/lacions d'Ofiüc i de la Balena}

És possible que amb tant de bestiar voltant pel cel, algunes constel-lacions s'hagin perdut. Les ovelles descarriades són la constel-lació d'Ofiüc i la de la Balena. Ofiüc és situada a la franja zodiacal sobre la mateixa eclíptica, entre Sagitari i l'Escorpió (figura 4). És visible des d'ambdós hemisferis terrestres i representa el déu de la medicina, Ofiüc, agafant una serpent, que és el símbol dels poders curatius. De la posició del Sol es pot concloure que les persones nascudes entre el $2 \mathrm{i}$ el 21 de desembre no pertanyen a cap signe solar, i, conseqüentment, no estan influenciades pel destí que les estrelles escriuen sobre els mortals.

Ofiüc també té la particularitat que el Sol hi és més temps al seu interior (19 dies) que no pas a la constel-lació de l'Escorpió (9 dies).

La constel-lació de la Balena es troba entre Peixos i Aquari i frega, pel seu extrem nord-oest, l'eclíptica.

¿Com és que la pràctica totalitat d'astròlegs mai es prenen seriosament Ofiüc i la Balena i segueixen amb els dotze signes zodiacals clàssics (NAVARRETE, 2001), quan n'haurien de fer servir catorze? Potser la resposta es troba en el fet que l'any té dotze mesos i no catorze. De fet, tampoc resulta estrany que Navarrete (2001) encara no sàpiga ben bé quants són els signes del zodíac ja que, només durant l'any 2001, ha publicat 25 llibres astrològics amb l'editorial Harlequín.

L'amplada de les constel/lacions eclíptiques

Una altra inconsistència zodiacal és que no hi ha 


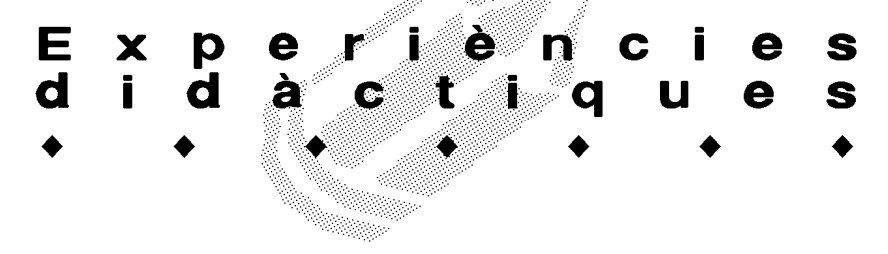

cap constel-lació eclíptica que tingui una amplada angular de $30^{\circ}$ (Taula 1). L'interval eclíptic varia des dels $0^{\circ}$ de la Balena fins als $44,0^{\circ}$ de Verge. La constel-lació que s'apropa més als $30^{\circ}$ és Capricorn, amb $29,5^{\circ}$.

El fet que els $30^{\circ}$ siguin una constant astrológica és una conseqüència directa de l'adopció d'un zodíac de 12 signes. És interessant saber que diverses cultures al Ilarg de la història han emprat, com a mínim, deu esquemes diferents de divisió zodiacal, que van des dels 6 signes dels habitants primitus de la zona de l'Eufrates fins als 28 signes de la cultura xinesa.

\section{Planetes antics i moderns}

Des de l'època de Claudi Ptolemeu, autor del llibre més important d'astrologia de l'antiguitat, el Tetrabiblon, fins a una data relativament recent, els astròlegs van fer servir un conjunt limitat i ben definit de cossos celests del sistema solar per fer les prediccions. El Sol, la Lluna i els cinc planetes visibles a ull nu: Mercuri, Venus, Mart, Júpiter i Saturn (encara que hi ha un sisè planeta visible a simple vista: Plutó). Durant aquest temps, tots els experts en endevinació astromàntica, des del mencionat Ptolemeu fins a William Lilly, passant pels famosos Michel de Nostradamus i Morin de Villefranche, buscaren -i trobaren- la "indubtable influència" d'aquests objectes astronòmics en les cartes astrals que dibuixaven. Curiosament, aquests eren els mateixos cossos que

$\begin{array}{lc}\text { Constel-lació } & \text { Interval eclíptic/ }{ }^{\circ} \\ \text { Verge } & 44,0 \\ \text { Peixos } & 37,5 \\ \text { Taure } & 36,5 \\ \text { Lleó } & 35,5 \\ \text { Sagitari } & 33,5 \\ \text { Capricorn } & 29,5 \\ \text { Bessons } & 28,5 \\ \text { Aries } & 24,5 \\ \text { Balança } & 23,0 \\ \text { Aquari } & 22,5 \\ \text { Càncer } & 20,0 \\ \text { Serpent-Ofiuc } & 18,0 \\ \text { Escorpió } & 7,0 \\ \text { Balena } & 0,0\end{array}$

Taula 1. Amplada angular de les 14 constel-lacions eclíptiques

estudiava l'astronomia, encara que des d'un punt de vista més convencional i diametralment oposat.

El 1781, William Herschel, mestre de música i astrònom afeccionat, descobrí un nou planeta: Urà. El 1846 es descobrí Neptú i el 1930, Plutó. Als astròlegs moderns els ha faltat temps per "apropiar-se" dels tres planetes descoberts per l'astronomia (encara que els més tradicionalistes prefereixen usar els vells $\mathrm{i}$ "comprovats" planetes [HARTMAN, 2000]). És obvi que si els primers ho fan així és perquè pressuposen que els últims planetes

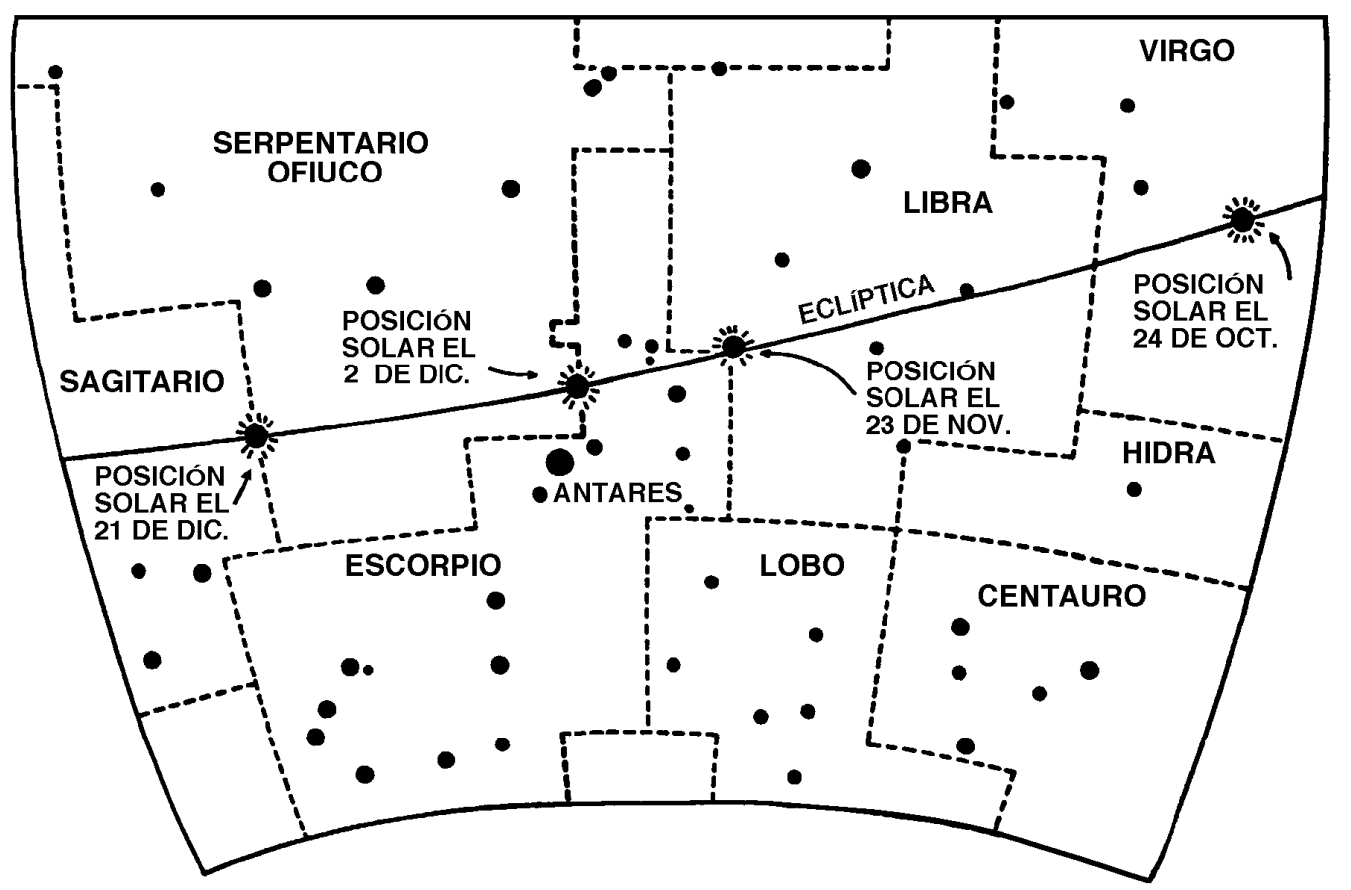

Fig. 4. Trajectòria aparent del Sol entre les estrelles fixes des del 24 d'octubre al 21 de desembre (CULVER, 1984) 


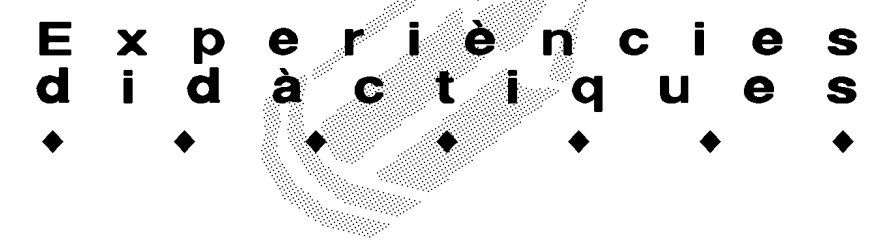

incorporats tenen alguna misteriosa influència sobre els destins dels mortals. El que resulta realment estrany és que els seus antecessors mai no notessin les influències abans que l'astronomia els descobrís, malgrat que ja porten molts milions d'anys donant voltes pel cel. I per acabar l'apartat, una curiositat: Els astròlegs diuen que Plutó és el regent astrològic de l'Escorpió (LE SCOUÉZEC, 1973). El que potser no saben és que quan es va descobrir (el 1930), Plutó era a la constel-lació dels Bessons. I ara és a la d'Ofiüc. Per tant, encara no ha entrat a la constel-lació de la qual n'és regent: I’Escorpió!

\section{Astres generacionals}

El corpus astrològic han inventat diverses excuses per justificar l'omisió mil·lenària d'Urà, Neptú i Plutó en les prediccions astrològiques. La més utilitzada és la de considerar-los astres generacionals. Atès el seu llarg període de revolució al voltant del Sol, tarden molts anys a passar d'un signe a l'altre, per tant, la seva influència no es notarà en els individus sinó en les generacions. És obvi que aquesta argumentació és fal-laç en diversos aspectes.

El període orbital d'Urà és, aproximadament, de 84 anys. Això vol dir que, de forma aproximada, dins de cada signe hi està al voltant de 7 anys. Per tant, cada set anys una influència estranya desapareixeria d'un signe i passaria a un altre, per exemple, dels Peixos a Àries. És absurd que una influència que migra d'un signe a un altre en un període tan curt es qualifiqui de generacional. El mateix podria argumentar-se per a Saturn, que roman en cada signe dos anys i mig. I si parlem de Neptú, la situació no és gaire diferent: tarda una mica menys de 165 anys a completar una volta al Sol, estant-se uns catorze anys a cada signe. En el lapse d'una vida humana de 70 anys, Neptú avançaria cinc signes. Cada set anys per al cas d'Urà i cada catorze per a Neptú, s'hauria d'observar la desaparició d'una influència específica en els nascuts en un signe per aparèixer misteriosament en els que neixen en el signe següent. ¿Com és que cap dels astròlegs d'èlit mai ha detectat el fenomen?

\section{Cossos astrològics}

L'ús que fan de Plutó els astròlegs moderns en les cartes astrals fa pensar en una altra qüestió de naturalesa diferent ¿Quin és el criteri seguit per decidir si un cos celest és -o no- significatiu astrològicament parlant? ¿Qui influeix i qui no? Els asteroides, per exemple, pràcticament no es tenen en compte, malgrat que alguns són de mida considerable (Ceres té un diàmetre de 914 quilòmetres, quasi la meitat del de Plutó, i és més a prop que ell, ja que es troba a 414 milions de quilòmetres del Sol). Alguns dels satèl-lits de Júpiter i deSaturn són bastant més grans que Plutó, però tampoc compten (Plutó és més petit que set satèl-lits del sistema solar).

Per complicar encara més les coses, ni tan sols es pot establir com a criteri general que un objecte serà cos astrològic quan l'òrbita descrita sigui dins del zodíac. En el cas de Plutó, que té un pla orbital amb una inclinació de $17,2^{\circ}$ respecte al pla de l'eclíptica, se surt fora del zodíac durant una bona part del temps que erràticament volta pel cel.

Sembla que el criteri per a decidir si un cos és o no significatiu és que sigui considerat "planeta" astronòmicament parlant, encara que amb els asteroides no regeix aquesta regla, ja que de vegades la ciència els cataloga com a planetes menors, ateses les seves menors dimensions.

El Sol i la Lluna són una excepció, perquè no són planetes, però l'astrologia justifica la seva influència en I'horòscp i en la carta astral dient que es fa servir l'antic model geocèntric de Ptolemeu (model que considera la Terra com el centre de l'univers). De fet, hi ha alguna periodista convertida en astròloga, que això dels planetes no ho té prou clar, ja que diu: "malgrat que, durant segles, l'astrologia ha operat amb els cinc planetes clàssics, els grans descobriments aportats per l'astronomia fan possible que, actualment, se n'hi hagin pogut incorporar cinc més: El Sol, la Lluna, Urà, Neptú i Plutó" (GALLOTTI, 1989).

\section{Quiró, el centaure astronòmic i astrològic}

El 1977, Charles T. Kowall descobrí un curiós objecte orbitant entre Saturn i Urà. Inicialment es pensà que podia ser un asteroide, però també es veié que es comportava com un cometa. El mateix Kowall proposà que es bategés amb l'evocador nom de Quiró. La mitologia grega ens recorda que Quiró fou el més savi dels centaures; però en aquest cas el que es volia destacar

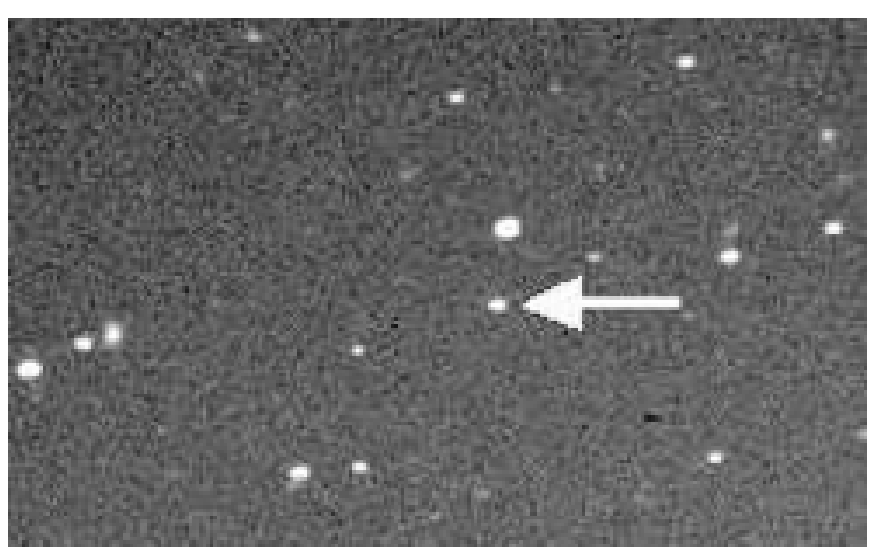

Figura 5. Quiró, el més gran dels centaures 


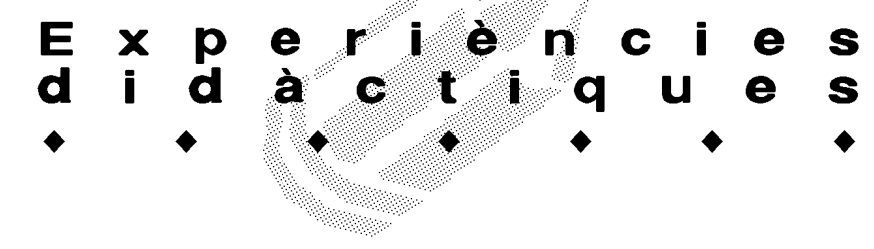

era l'aparent naturalesa dual de l'objecte: meitat asteroide i meitat cometa.

Quiró no està sol. És el primer (i el més gran, fins avui) d'una extensa família d'objectes nous, anomenats centaures. Ja n'hi ha 63 de descoberts i sis d'ells tenen noms de la mitologia grega: Quiró, Chariklo, Asbolus, Nessus, Hylonome i Pholus. Sens dubte, els centaures deuen ser objectes interessants, astronòmicament parlant. El que no resulta tan obvi és que l'interès sigui compartit per l'astrologia. Comptat i debatut, el Quiró astronòmic és un cos molt petit (més que vuit dels asteroides coneguts), força llunyà, del qual encara es desconeixen moltes coses.

Als astròlegs d'embranzida els va faltar temps per precipitar-se sobre el nadó. Al cap d'un any del naixement astronòmic -1978- la Astrologers Guil of America formà el Chiron Commitee. Cinc anys més tard, al 1983, Zane B. Stein publicà el llibre Interpreting Chiron; i Richard Nolle, Chiron: The New Planet in your Horoscop. De 1987 és Chiron: Rainbow Bridge Betwen the Inner and Outer Planets, de Barbara Clow. I al 1989, Melanie Reinhart trauria de la impremta: Chiron and the Healing Journey: an astrological and psychological perspective.

Quiró tardà una mica més a arribar a les editorials espanyoles. Sauzea (1989), introduí el nou "planeta" en la bibliografia hispànica; i dos anys més tard, Reinhart (1991) explicà el significat i simbolisme de Quiró en un manual de 426 pàgines.

Quiró ja compta amb una llarga llista de propietats astrològiques comprovades, malgrat que és un jove de només 24 anys. El Quiró mitològic era fill de Cronos i Filira; el seu naixement fou difícil i doloròs, i com que era un ésser monstruós fou abandonat per la seva mare. L'educaren Apolo i Artemisa. Fou mestre d'herois com Heracles i Aquiles. Quiró fou un reconegut sanador de ferides. Al Quiró astrològic se'l relaciona amb les persones que després d'experimentar el dolor es converteixen en sanadors. També representa la sanació mental, emocional i espiritual.

\section{El mite del signe solar}

Cap altre concepte astrològic és més universal i durador que la idea que les característiques humanes estan determinades, en bona part, pel signe solar de cada individu. La revisió de la literatura astrològica revela una classificació constant dels individus en funció del seu signe solar. En funció de la font astrològica consultada, el signe solar està suposadament relacionat amb els següents components de la constitució de cadascú: els trets característics de la personalitat, l'aparença física, les característiques fisiològiques, la carrera professional, els problemes de salut i la compatibilitat afectiva amb altres persones.
La simplicitat dels conceptes astrològics relacionats amb el signe solar fa que, per una banda, tinguin una gran popularitat. Però per l'altra, també permet fer comprovacions empíriques força senzilles. L'únic que cal fer és agafar una mostra de persones d'acord amb el seu signe solar i veure si les suposades correlacions es verifiquen.

A títol d'exemple, s'analitzaran tres casos diferents: el primer fa referència a les característiques físiques; el segon, a la professió; i el tercer, a la compatibilitat amorosa.

Culver (1984) descriu un cas que té a veure amb l'aparença física d'un individu. Segons un manual d'astrologia, les característiques físiques d'una persona Aries són: "Un cuello largo como el de una oveja; una semblanza con el símbolo astrológico en la formación de las cejas y de la nariz; cejas bien marcadas; aspecto colorado, sano; cabello rojo, andar activo".

Per provar si els Aries són pèl-roigs, es realitzà una enquesta entre 300 persones pèl-roges en la qual cada individu es catalagova en funció del seu signe solar. El resultat de l'enquesta es mostra a la taula 2. Davant els resultats, dues coses resulten òbvies. En primer Iloc, el signe solar Aries no té un significat especial en el fet del nombre de persones pèl-roges que hagin nascut sota aquest signe. En segon lloc, cap signe solar predomina sobre la resta de signes.

Molts astròlegs insisteixen en el fet que el signe solar d'una persona es correlaciona fortament amb la seva vocació professional. Franknoi (1989) descriu una investigació feta pel físic John McGervey, de la universitat Case Western Reserve, en la qual buscà les biografies $i$ dates de naixement d'uns 6000 polítics i de 17000 científics per tal de veure si els membres d'aquestes professions s'agrupaven al voltant de certs signes, com

$\begin{array}{lc}\text { Signe solar } & \begin{array}{c}\text { Nombre de } \\ \text { persones pèl-roges }\end{array} \\ \text { Aries } & 27 \\ \text { Taure } & 22 \\ \text { Bessons } & 25 \\ \text { Càncer } & 28 \\ \text { Lleó } & 30 \\ \text { Verge } & 21 \\ \text { Balança } & 34 \\ \text { Escorpió } & 23 \\ \text { Sagitari } & 21 \\ \text { Capricorn } & 31 \\ \text { Aquari } & 20 \\ \text { Peixos } & 18\end{array}$

Taula 2. Signe solar al qual pertanyen 300 pèl-rojos 


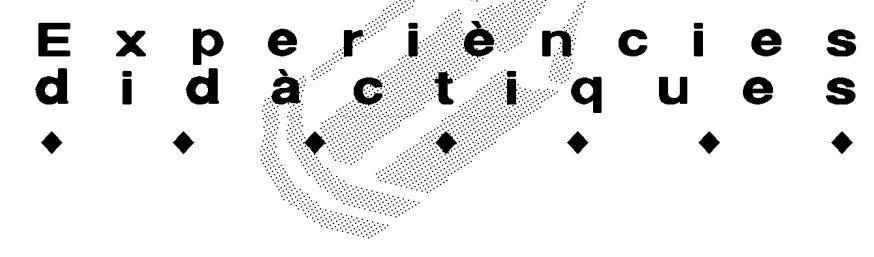

prediuen els astròlegs. El resultat obtingut indicava que els signes d'ambdós grups es trobaven distribuïts de forma aleatòria.

Una conseqüència lògica de la creença astrològica en la correlació entre personalitat i signe solar és la idea que certes combinacions de signes solars (i, per tant, de personalitat) fan que existeixin relacions bones o compatibles entre les persones, mentre que altres combinacions condueixen a relacions incompatibles. Amb aquest plantejament, resulta fàcil donar consells sobre l'amor i el matrimoni segons la compatibilitat astrològica. De fet, a la literatura astrològica existeixen fortes discrepàncies sobre quines són les parelles de signes compatibles i quines les incompatibles. Culver (1984) posa com a exemple les incompatibilitats de signes segons dos astròlegs diferents (Fig. 5).

En primer lloc, crida l'atenció la discrepància entre els dos astròlegs. Només coincideixen en 15 parelles incompatibles. En segon lloc, si es considera el divorci com una mesura de la incompatibilitat d'una parella, seria possible saber, realment, quins són els signes incompatibles si es fes un estudi de quin signe tenen les parelles divorciades. Aquest estudi es va fer a l'estat de Michigan (EEUU) i a Amsterdam (Holanda). En ambdós casos els resultats estadístics indicaven que cap de les combinacions de signes solars presentaven percentatges de divorcis que fossin significatius. En altres paraules, cap dels 144 quadrets de la figura 5 es poden marcar de forma que tinguin significat estadístic.

\section{A tall de conclusió}

Amb tot el que s'ha exposat fins ara es pot concloure que l'astrologia no presenta cap de les característiques que ha de tenir una ciència. L'astrologia -si és que només es pot parlar d'una sola astrologia- no fa servir les evidències objectives ni utilitza els mètodes experimentals de verificació per tal de fer observacions que validin les seves idees. Tampoc no es canvia la "teoria" astrològica quan la realitat contradiu les prediccions astrològiques. Potser les persones que creuen en l'astrologia no volen veure que el món és com és i no com els agradaria que fos. Potser es prefereixen les respostes còmodes, les veritats que no canvien i que es fonamenten en les creences personals. La majoria d'astròlegs estan satisfets amb la il-lusió que "l'astrologia serveix". Els cels tenen una història diferent per explicar. Es tracta d'una història molt més bonica, majestuosa, complicada i excitant que la de la faula astrològica. I té a veure amb fets, i no amb ficcions.

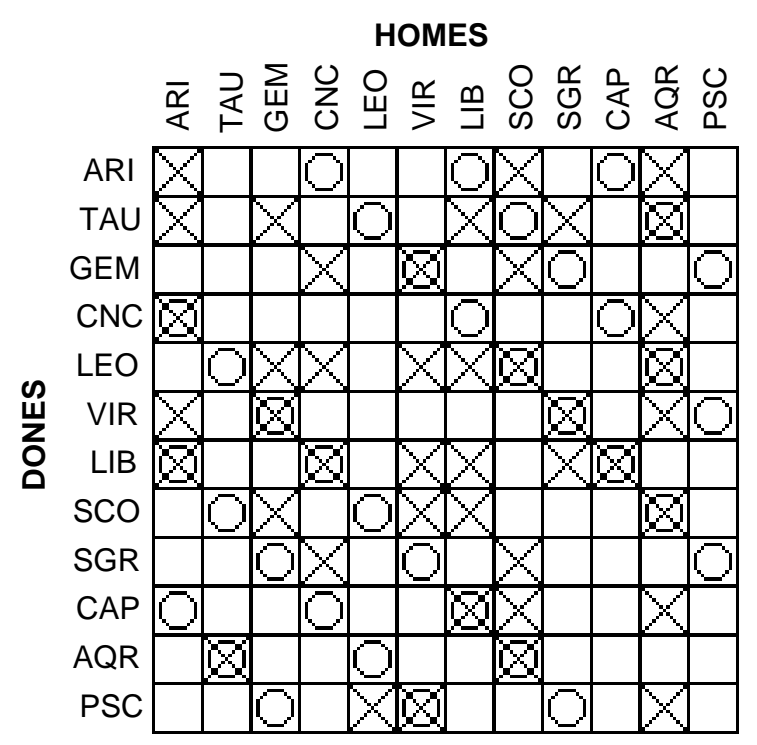

Figura 5. Incompatibilitat amorosa de signes solars, segons dos astròlegs diferents: X (Teri King) i O (Sidney Omar)

\section{Referències bibliogràfiques}

CULVER, R.B. i IANNA, P.A. E/ secreto de las estrellas. Astrología: ¿mito o realidad? Edit. Tikal. Girona. 1984.

FRANKNOI, A. Your Astrology Defense Kit. «Sky \& Telescope», agost (1989) 146.

GALLOTTI, A. La astrología. Colección Guías Prácticas. Edit. T.I.S.A., La Vanguardia. Barcelona. 1989.

HARTMAN, F. Principios de geomancia astrológica. Ediciones Obelisco. Barcelona. 2000.

HINOSTROZA, R. El sistema astrológico. Teoría y práctica.

Barral Editores. Barcelona. 1972.

KINDERSLEY, D. Encicopledia del espacio y del universo (colección virtual). Edit. Zeta Multimedia. Barcelona. 1996.

LE SCOUÉZEC, G. Astrología y geomancia. Ediciones Martínez Roca. Barcelona.1973

NAVARRETE VARELA, P. Los doce signos del zodíaco, 2002. Edit. Harlequín Ibérica. Madrid. 2001.

REINHART, M. Significado y simbolismo de Quirón. Ediciones Urano. Barcelona. 1991.

SAUZEA, B. Quirón, el nuevo planeta. Ediciones Obelisco. Barcelona. 1989. 